\title{
Exposure to multiple sources of polycyclic aromatic hydrocarbons and breast cancer incidence
}

\author{
Alexandra J. White ${ }^{\mathrm{a}, *}$, Patrick T. Bradshaw ${ }^{\mathrm{b}}$, Amy H. Herring ${ }^{\mathrm{c}}$, Susan L. Teitelbaum ${ }^{\mathrm{d}}$, Jan Beyea ${ }^{\mathrm{e}}$, \\ Steven D. Stellman ${ }^{\mathrm{f}}$, Susan E. Steck ${ }^{\mathrm{i}}$, Irina Mordukhovich ${ }^{\mathrm{a}}$, Sybil M. Eng ${ }^{\mathrm{f}}$, Lawrence S. Engel ${ }^{\mathrm{a}}$, \\ Kathleen Conway ${ }^{a}$, Maureen Hatch ${ }^{\mathrm{j}}$, Alfred I. Neugut ${ }^{\mathrm{f}, \mathrm{g}}$, Regina M. Santella ${ }^{\mathrm{h}}$, Marilie D. Gammon ${ }^{\mathrm{a}}$ \\ a Department of Epidemiology, University of North Carolina, Chapel Hill, NC, USA \\ b Department of Nutrition, University of North Carolina, Chapel Hill, NC, USA \\ c Department of Biostatistics, University of North Carolina, Chapel Hill, NC, USA \\ d Department of Preventive Medicine, Ichan School of Medicine at Mt. Sinai, New York, NY, USA \\ e Consulting in the Public Interest (CIPI), Lambertville, NJ, USA \\ ${ }^{\mathrm{f}}$ Department of Epidemiology, Columbia University, USA \\ ${ }^{g}$ Department of Medicine, Columbia University, USA

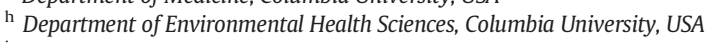 \\ ${ }^{i}$ Department of Epidemiology and Biostatistics, University of South Carolina, Columbia, SC, USA \\ j Division of Cancer Epidemiology and Genetics, Radiation Epidemiology Branch, National Cancer Institute, Bethesda, MD, USA
}

\section{A R T I C L E I N F O}

\section{Article history:}

Received 27 October 2015

Received in revised form 3 February 2016

Accepted 4 February 2016

Available online $\mathrm{xxxx}$

\section{Keywords:}

Breast cancer

Polycyclic aromatic hydrocarbons

Smoking

Environmental tobacco smoke

Grilled meat

Indoor air

Outdoor air

\begin{abstract}
A B S T R A C T
Background: Despite studies having consistently linked exposure to single-source polycyclic aromatic hydrocarbons (PAHs) to breast cancer, it is unclear whether single sources or specific groups of PAH sources should be targeted for breast cancer risk reduction.

Objectives: This study considers the impact on breast cancer incidence from multiple PAH exposure sources in a single model, which better reflects exposure to these complex mixtures.

Methods: In a population-based case-control study conducted on Long Island, New York ( $N=1508$ breast cancer cases/1556 controls), a Bayesian hierarchical regression approach was used to estimate adjusted posterior means and credible intervals ( $\mathrm{CrI}$ ) for the adjusted odds ratios (ORs) for PAH exposure sources, considered singly and as groups: active smoking; residential environmental tobacco smoke (ETS); indoor and outdoor air pollution; and grilled/smoked meat intake.

Results: Most women were exposed to PAHs from multiple sources, and the most common included active/passive smoking and grilled/smoked food intake. In multiple-PAH source models, breast cancer incidence was associated with residential ETS from a spouse $(\mathrm{OR}=1.20,95 \% \mathrm{CrI}=1.03,1.40)$ and synthetic firelog burning ( $\mathrm{OR}=$ $1.29,95 \% \mathrm{CrI}=1.06,1.57$ ); these estimates are similar, but slightly attenuated, to those from single-source models. Additionally when we considered PAH exposure groups, the most pronounced significant associations included total indoor sources (active smoking, ETS from spouse, grilled/smoked meat intake, stove/fireplace use, $\mathrm{OR}=1.45,95 \% \mathrm{CrI}=1.02,2.04)$.

Conclusions: Groups of PAH sources, particularly indoor sources, were associated with a $30-50 \%$ increase in breast cancer incidence. PAH exposure is ubiquitous and a potentially modifiable breast cancer risk factor.
\end{abstract}

(c) 2016 Elsevier Ltd. All rights reserved.

\section{Introduction}

Breast cancer is the most commonly diagnosed cancer among women in the U.S. (American Cancer Society, 2014). Experimental research suggests that polycylic aromatic hydrocarbons (PAHs) induce

* Corresponding author at: Department of Epidemiology, CB\#7435, McGavranGreenberg Hall, University of North Carolina, Chapel Hill, NC 27599-7435, USA.

E-mail address: whitea@unc.edu (A.J. White). mammary tumors (IARC, 2010), but associations in women are understudied. Humans are exposed to PAHs across the life course from multiple sources, including cigarette smoking, environmental tobacco smoke (ETS), diet, indoor and outdoor air pollution (Boström et al., 2002). PAHs are formed from the incomplete combustion of organic material and are confirmed carcinogens to the human lung (IARC, 2010).

Previous population studies have observed positive associations between short-term PAH biomarker concentrations (i.e., PAH-DNA 
adducts) and breast cancer incidence (Gammon et al., 2004b; Li et al., 2002; Rundle et al., 2000). However, it is unclear from biomarker studies which PAH sources are the predominant contributors to these associations. As long-term carcinogen exposure is considered to be most relevant, other studies have considered single PAH exposure sources and have found increases in breast cancer risk with active cigarette smoking (Gaudet et al., 2013), long-term residential ETS (Gammon et al., 2004a; Laden and Hunter, 1998; Morabia et al., 1996), indoor air pollution from burning synthetic logs (White et al., 2014), outdoor air pollution (Bonner et al., 2005; Crouse et al., 2010; Lewis-Michl et al., 1996; Mordukhovich et al., 2016; Nie et al., 2007; Raaschou-Nielsen et al., 2011), and intake of grilled and smoked foods (Di Maso et al., 2013; Fu et al., 2011; Steck et al., 2007).

Our understanding of the impact of PAHs on breast cancer may be improved if these multiple sources are considered simultaneously (2015). The relative contribution of PAH sources to an individual's exposure is unknown (Boström et al., 2002). Tobacco smoke is likely the largest contributor (Menzie et al., 1992), but diet is the predominant source among non-smokers (Boström et al., 2002). However, carcinogenic potency is hypothesized to vary by route of exposure (Menzie et al., 1992), metabolic pathway and type of PAH (Boström et al., 2002). Thus, it is unclear whether certain sources, groups of sources, or all PAH sources should be targeted for breast cancer risk reduction.

The study reported here aims to consider, in a single hierarchical regression model, the impact of multiple long-term PAH sources on breast cancer incidence. Variables from the same exposure source (for example, different measures of grilled/smoked meat intake) are highly correlated. A hierarchical regression approach permits the consideration of multiple PAH source exposures in a single multivariable model, while accounting for similar sources of the PAH exposures. Additionally, with a single statistical model we are able to estimate the OR for groups of PAH sources, or PAH exposure profiles, based on contrasting a priori defined exposure groups of interest.

\section{Methods}

The study reported here builds upon the population-based casecontrol resources of the Long Island Breast Cancer Study Project (LIBCSP), for which extensive methods have been previously published (Gammon et al., 2002). IRB approval was obtained from all relevant institutions. Written signed informed consent was obtained from all participants.

\subsection{Study population}

The cases are English-speaking female residents of Long Island, New York who were diagnosed with their first primary in situ or invasive breast cancer between August 1st, 1996 and July 31st, 1997. Cases were identified using rapid case ascertainment. Controls were women without a history of breast cancer who were frequency matched on the expected 5-year age distribution of the cases. Controls were identified using random digit dialing for those $<65$ years of age and by using Health Care Finance Administration Rosters for those 65 years of age and older.

\subsection{PAH exposure sources assessment}

Five binary PAH exposure sources were assessed across the life course. Active smoking, residential ETS, grilled/smoked meat intake, and indoor wood-burning stove/fireplace use were assessed by structured questionnaire (Gammon et al., 2004a; Steck et al., 2007; White et al., 2014) with a trained interviewer, and vehicular traffic exposure was assessed using a validated historical geographic model (Beyea et al., 2006; Mordukhovich et al., 2016). Continuous variables required categorization because associations with breast cancer were neither non-linear nor log-linear and were dichotomized in order to facilitate interpretation and scaling in the hierarchical regression across $\mathrm{PAH}$ sources.

Active smoking (ever, never) was defined as smoking at least 1 cigarette per day for 6 months or longer, and current active smoking (yes, no) was defined as smoking within the last 12 months prior to diagnosis or referent date for controls (= date of identification). Smoking prior to first birth (yes, no) was determined by using age at first birth and age at which participant first starting smoking. Participants were asked if they had lived with a smoker to determine ETS exposure (yes, no) and their relationship to that person to evaluate if they lived with a smoking spouse (yes, no). Indoor stove/fireplace use was defined as having used a stove/fireplace in a Long Island residence for at least 3 times per year (yes, no) and whether or not participants burned wood (yes, no) and/or synthetic logs (yes, no).

Continuous variables for the PAH sources were dichotomized using cutpoints that best reflected previous associations observed with breast cancer incidence (Mordukhovich et al., 2016; Steck et al., 2007). Frequency of intake of grilled/smoked meat was assessed for six decades across the life course. Lifetime intake was defined as the average servings consumed per year based on quantile distributions of consumption in the controls, as follows: for total grilled/barbecued and smoked meats $(<55$ servings/year, $55+$ servings/year); grilled/barbecued beef, pork and lamb $(<14$, $14+$ servings/year); and smoked beef, pork and lamb $(<22$, $22+$ servings/year). The geographic model for vehicular traffic exposure incorporated historical U.S. vehicular PAH emissions data, information on traffic and transportation patterns, Long Island meteorological variables and pollutant dispersion factors to determine vehicular traffic exposure in 1995, the year prior to LIBCSP recruitment (low risk $=<95$ th percentile, high risk $=\geq 95$ th percentile). Previously, we found the association with breast cancer to be limited to the top 5\% of those exposed to vehicular traffic (Mordukhovich et al., 2016).

\subsection{Confounder assessment}

A directed acyclic graph was used to identify a minimally sufficient set to control for confounding (Glymour and Greenland, 2008) (Supplemental Fig. I).

The odds ratios were adjusted for the following covariates, which were assessed by structured questionnaire (Gammon et al., 2002): age at menarche ( $\leq 12,>12$ years); parity (nulliparous, parous); lifetime alcohol intake (non-drinkers, $<15$ g/day, 15 g-30 g/day, $\geq 30$ g/day); education (high school graduate or less, some college, college or postcollege); income $(<\$ 34,999, \$ 35,000-\$ 69,999, \geq \$ 70,000)$; and the frequency matching factor, 5 -year age group.

\subsection{Statistical analysis}

To examine the associations between the main PAH sources and $\mathrm{PAH}$ groups and breast cancer risk, 12 binary PAH exposure variables were considered. For our primary analysis, these 12 variables were characterized according to five exposure sources: (1) active smoking: ever active smoking, current active, smoking prior to first pregnancy; (2) residential ETS: any residential ETS, residential ETS from spouse; (3) indoor stove and/or fireplace use: any stove/fireplace use, wood burning, synthetic log burning; (4) diet: total grilled/barbecued and smoked meats, smoked beef, pork and lamb and grilled/barbecued beef, pork and lamb; and (5) vehicular traffic. Estimating associations with the PAH exposure variables by these five exposure sources facilitates understanding which of these sources to prioritize for reduction from a public health standpoint.

All models were specified in a Bayesian framework and we calculated posterior means for the ORs and corresponding 95\% posterior credible intervals ( $\mathrm{CrI}$, the Bayesian analog to a confidence interval) 
(Gelman and Hill, 2006). The risk of breast cancer was specified using logistic regression.

$\operatorname{logit}[\operatorname{Pr}(\mathrm{Y}=1 \mathrm{IX}, \mathrm{W}, \beta, \gamma)]=\alpha+\mathrm{X} \beta+\mathrm{W} \gamma$

where $Y$ is case status, $\mathrm{X}$ denotes the individual $\mathrm{PAH}$ exposures, and $\mathrm{W}$ is a vector of confounders. The $\beta$ coefficient represents the association [ln $(\mathrm{OR})]$ of the individual PAH sources with breast cancer.

Hierarchical regression builds upon this first-level model by specifying a second-level model that incorporates information on the PAH sources that may explain the individual $\mathrm{PAH}$-exposure associations (Gammon et al., 2004a; Mordukhovich et al., 2016; Steck et al., 2007; White et al., 2014). The second level of the hierarchical regression for the logistic coefficient $\beta$ is:

$\beta=\mathrm{Z} \pi+\delta$

where $\mathrm{Z}$ is the second-stage design matrix (Supplemental Table I) with each row corresponding to a $\beta$ from the first-stage model and each column corresponding to an exposure source, which encodes our prior information about the PAH exposure variables and their respective sources. The $4 \times 1$ coefficient vector $\pi$ corresponds to the associations between the second stage covariates (PAH exposure source) and the log-OR with breast cancer and $\delta$ is assumed to be normally distributed with a mean $=0$ and a variance $=\tau^{2}$. This approach accounts for a degree of similarity of PAH exposures that come from similar sources while allowing some residual variation $(\delta)$ associated with these effects. If the PAH exposure variables were thought to be related to a particular source they were scored as 1 , otherwise were coded as 0 . As only one variable was available for vehicular traffic, there was no column in the $Z$-matrix for it and thus, it effectively serves as its own source.

Combining these equations allows for estimation of the association between each PAH variable, according to $\mathrm{PAH}$ source, and breast cancer:

$\operatorname{logit}[\operatorname{Pr}(\mathrm{Y}=1 \mathrm{IX}, \mathrm{Z}, \mathrm{W})]=\alpha+\mathrm{XZ} \pi+\mathrm{X} \delta+\mathrm{W} \gamma$,

where, from this mixed-model specification, the $\pi$ and $\gamma$ correspond to fixed effects of the PAH sources and confounders, respectively, and $\delta$ contains the random exposure-level effects (Gelman and Hill, 2006; Greenland, 2000; Witte et al., 1994).

For the intercept $(\alpha)$, and covariate coefficients ( $\pi$ and $\gamma$ ), a relatively non-informative normally-distributed prior was used (mean $=0$, variance $=1000$ ). For $\tau$, a uniform prior from 0.01 to 100 was used. We specified an additional model to account for the approximately $15 \%$ of the 1995 vehicular traffic data that were missing. Missing data are accommodated in a Bayesian framework in a method similar to multiple imputation by specifying a distribution for the variable with missing data (Ibrahim et al., 2005; Ibrahim et al., 2012). In this case, the indicator of high vehicular traffic level was modeled from a logistic regression with covariates income, education, and age, with relatively noninformative normal priors on their coefficients (mean $=0$, variance $=$ 1000). In addition to this hierarchical model, for comparison, we also estimated single exposure and multivariable models (only estimating $\alpha, \beta$ and $\gamma$ from the first stage model without specifying a second-stage model). For the single exposure model, each PAH variable was modeled alone; for the multivariable model, all individual exposures were included simultaneously. These methods correspond to those employed in similar analyses (Bradshaw et al., 2013; Hung et al., 2004).

From the hierarchical model, the posterior mean of the OR and corresponding $95 \% \mathrm{CrI}$ for $\mathrm{PAH}$ exposure profiles of interest relative to women who had low PAH exposure were estimated by calculating linear combinations of the relevant $\beta$ coefficients (Supplemental Table II). These ORs were calculated from the estimates produced by the hierarchical regression model. These profiles, which are not mutually exclusive, were predetermined to facilitate interpretation by considering typical or potentially informative patterns of exposure across the $12 \mathrm{PAH}$ measures. The profiles that span across PAH sources were chosen in part based on classifications that had sufficient numbers of cases and controls to estimate associations. The PAH exposure profiles of interest were defined as: (1) the referent of low PAH exposure (non-smokers, no residential ETS, low intake of grilled/smoked foods ( $<$ 55 servings/year total grilled/barbecued and smoked meats, $<14$ servings year of grilled/barbecued beef, pork and lamb, $<22$ servings year of smoked beef, pork and lamb), low risk vehicular traffic $(<95$ th percentile), and no stove/fireplace use); (2) tobacco smoke (current, active smokers who started prior to first pregnancy and were exposed to residential ETS from a spouse); (3) ingested PAHs (high intake of overall grilled/smoked foods (55 + servings/year), grilled/barbecued beef, pork and lamb (14+ servings/year), and smoked beef, pork and lamb (22+ servings/year)); (4) indoor stove/fireplace users (indoor stove/ fireplace users who burned both wood and synthetic logs); (5) inhaled PAHs (active smokers, residential ETS, high risk vehicular traffic (top 5th percentile), stove/fireplace users); (6) indoor source PAHs (active smokers, residential ETS from spouse, high overall grilled/smoked foods ( $55+$ servings/year), and stove/fireplace users); (7) five PAH sources (active smokers, residential ETS, high overall grilled/smoked foods ( $55+$ servings/year), stove/fireplace users and high risk vehicular traffic exposure (top 5th percentile)). Sample sizes of cases and controls that were classified as exposed to each profile were determined to allow for interpretation of the prevalence in the study population of different combinations of PAH exposures. To estimate posterior probabilities, confounders were specified at their modal values (age: 50-54 years; income: $\$ 35,000-\$ 69,999$; education: high school or less; parity: parous; alcohol intake: $<15 \mathrm{~g} /$ day; age at menarche: $>12$ years) and PAH sources not specified in the definition of the profiles were set to the referent category.

\subsection{Sensitivity analyses}

The hierarchical model was also fit 5 times using 5 separate datasets with multiple imputed historical 1960-1990 vehicular traffic estimates (up to $20 \%$ missing data imputed) to compare results across the 5 datasets and from the model fit only with the 1995 estimates (Beyea et al., 2013). Another Z-matrix configuration was evaluated, where the second-level model included two routes of exposure, ingestion versus inhalation. This analyses was also repeated, limiting to women who were postmenopausal and had ER + tumors only.

Posterior means and credible intervals $(\mathrm{CrI})$ of the model parameters were estimated by sampling from their joint posterior distribution through Gibbs sampling (Casella and George, 1992) conducted using JAGS (Plummer, 2003) and the package R2jags (Su and Yajima, 2012) through the R language (R Foundation for Statistical Computing, Vienna, Austria). The $95 \% \mathrm{CrI}$ represents the 2.5 th and 97.5 th percentiles from the estimated posterior distribution for each parameter. $\mathrm{R}$ code for the hierarchical Bayes analysis is included in the supplement. The model had 30,000 iterations with a burn-in of 10,000 . Trace plots were visually examined to evaluate convergence.

\section{Results}

Women in this population-based sample from Long Island NY were heavily exposed to PAHs across multiple sources (Table 1). Approximately $20 \%$ were current smokers; almost $80 \%$ had at one time or another lived in a home with a smoker; over $70 \%$ consumed a serving or more per week of grilled/smoked foods and almost half used stove/fireplaces in their home.

ORs for breast cancer incidence were elevated for residential ETS from a spouse $(\mathrm{OR}=1.20,95 \% \mathrm{CrI}=1.03,1.40)$, total grilled $/$ smoked foods $(\mathrm{OR}=1.16,95 \% \mathrm{CrI}=0.97,1.38)$, vehicular traffic $(\mathrm{OR}=1.25$, $95 \% \mathrm{CrI}=0.85,1.76)$ and synthetic log burning $(\mathrm{OR}=1.29,95 \% \mathrm{CrI}=$ $1.06,1.57$ ) in the hierarchical model (Table 2 ). The hierarchical analyses, incorporating second-stage information about the PAH exposure source, resulted in more precise estimates than the multivariable 
Table 1

Distribution of demographic characteristics and PAH exposure measures for study participants, by case-control status, LIBCSP 1996-1997.

\begin{tabular}{|c|c|c|c|c|}
\hline & \multicolumn{2}{|c|}{ Controls $(N=1556)$} & \multicolumn{2}{|c|}{ Cases $(N=1508)$} \\
\hline & $\mathrm{N}$ & $(\%)$ & $\mathrm{N}$ & $(\%)$ \\
\hline \multicolumn{5}{|l|}{ Age group $^{a}$} \\
\hline$<35$ & 45 & $(2.9)$ & 39 & $(2.6)$ \\
\hline $35-44$ & 245 & (15.7) & 181 & $(12.0)$ \\
\hline $45-54$ & 423 & $(27.2)$ & 397 & $(26.3)$ \\
\hline $55-64$ & 403 & (25.9) & 372 & $(24.7)$ \\
\hline $65-74$ & 310 & (19.9) & 365 & $(24.2)$ \\
\hline $75-84$ & 112 & $(7.2)$ & 134 & $(8.9)$ \\
\hline $85+$ & 18 & $(1.2)$ & 20 & $(1.3)$ \\
\hline \multicolumn{5}{|l|}{ Income $^{a}$} \\
\hline$<\$ 34,999$ & 506 & $(32.6)$ & 531 & $(35.3)$ \\
\hline$\$ 35,000-\$ 69,999$ & 552 & (35.6) & 495 & $(32.9)$ \\
\hline$\$ 70,000+$ & 496 & (31.9) & 478 & $(31.8)$ \\
\hline \multicolumn{5}{|l|}{ Education $^{\mathrm{a}}$} \\
\hline High school grad or less & 676 & $(43.6)$ & 721 & $(48.0)$ \\
\hline Some college & 415 & (26.7) & 360 & $(24.0)$ \\
\hline College or post-college & 461 & (29.7) & 421 & $(28.0)$ \\
\hline \multicolumn{5}{|l|}{ Lifetime alcohol intake ${ }^{a}$} \\
\hline Non-drinkers & 605 & $(39.0)$ & 598 & $(39.7)$ \\
\hline lifetime intake $<15 \mathrm{~g} /$ day & 735 & $(47.3)$ & 691 & $(45.8)$ \\
\hline lifetime intake $15-30 \mathrm{~g} / \mathrm{day}$ & 119 & $(7.7)$ & 147 & $(9.7)$ \\
\hline lifetime intake $=>30 \mathrm{~g} /$ day & 94 & $(6.1)$ & 72 & $(4.8)$ \\
\hline \multicolumn{5}{|l|}{ Parity } \\
\hline Nulliparous & 171 & $(11.0)$ & 198 & $(13.1)$ \\
\hline Parous & 1385 & $(89.0)$ & 1310 & $(86.9)$ \\
\hline \multicolumn{5}{|l|}{ Age at menarche } \\
\hline$\leq 12$ & 686 & $(44.1)$ & 671 & $(44.5)$ \\
\hline$>12$ & 870 & $(55.9)$ & 837 & $(55.5)$ \\
\hline \multicolumn{5}{|l|}{ Ever active smoking ${ }^{\mathrm{b}}$} \\
\hline Never & 698 & $(44.9)$ & 675 & $(44.8)$ \\
\hline Ever & 855 & $(55.1)$ & 833 & $(55.2)$ \\
\hline Missing & 3 & & 0 & \\
\hline \multicolumn{5}{|l|}{ Current active smoking ${ }^{\mathrm{b}}$} \\
\hline No & 1262 & $(81.3)$ & 1218 & $(80.8)$ \\
\hline Yes & 291 & $(18.7)$ & 290 & (19.2) \\
\hline \multicolumn{5}{|l|}{$\mathrm{ETS}^{\mathrm{b}}$} \\
\hline Never & 328 & $(21.6)$ & 301 & $(20.5)$ \\
\hline Ever & 1188 & $(78.4)$ & 1170 & $(79.5)$ \\
\hline \multicolumn{5}{|l|}{ ETS from spouse ${ }^{\mathrm{b}}$} \\
\hline Never & 865 & $(57.1)$ & 752 & $(51.2)$ \\
\hline Ever & 650 & $(42.9)$ & 716 & $(48.8)$ \\
\hline \multicolumn{5}{|c|}{ Smoking before first pregnancy ${ }^{\mathrm{b}}$} \\
\hline No & 855 & $(54.9)$ & 859 & $(57.0)$ \\
\hline Yes & 701 & $(45.1)$ & 649 & $(43.0)$ \\
\hline \multicolumn{5}{|c|}{ Grilled/barbecued/smoked meat intake ${ }^{c}$} \\
\hline$\leq 54$ servings/year & 500 & $(34.6)$ & 427 & $(30.1)$ \\
\hline $55+$ servings/year & 944 & $(65.4)$ & 991 & $(69.9)$ \\
\hline \multicolumn{5}{|c|}{ Grilled/barbecued beef, pork and lamb ${ }^{c}$} \\
\hline$\leq 13$ servings/year & 569 & $(37.5)$ & 523 & $(35.2)$ \\
\hline $14+$ servings/year & 949 & $(62.5)$ & 962 & $(64.8)$ \\
\hline Smoked beef, pork and lamb & & & & \\
\hline$\leq 21$ servings/year & 774 & $(50.4)$ & 717 & $(48.4)$ \\
\hline $22+$ servings/year & 762 & $(49.6)$ & 763 & $(51.6)$ \\
\hline Vehicular traffic $1995^{\mathrm{d}}$ & & & & \\
\hline$<95$ th percentile & 1267 & $(95.0)$ & 1197 & $(94.0)$ \\
\hline$=>95$ th percentile & 67 & $(5.0)$ & 77 & $(6.0)$ \\
\hline Fireplace use $\mathrm{e}^{\mathrm{e}}$ & & & & \\
\hline Never & 781 & $(50.4)$ & 757 & $(50.3)$ \\
\hline Ever & 768 & $(49.6)$ & 747 & $(49.7)$ \\
\hline Wood burning ${ }^{\mathrm{e}}$ & & & & \\
\hline Never & 850 & $(54.9)$ & 830 & $(55.2)$ \\
\hline Ever & 699 & $(45.1)$ & 674 & $(44.8)$ \\
\hline
\end{tabular}

Table 1 (continued)

\begin{tabular}{|c|c|c|c|c|}
\hline & \multicolumn{2}{|c|}{ Controls $(N=1556)$} & \multicolumn{2}{|c|}{ Cases $(N=1508)$} \\
\hline & $\mathrm{N}$ & $(\%)$ & $\mathrm{N}$ & $(\%)$ \\
\hline \multicolumn{5}{|c|}{ Synthetic log burning ${ }^{\mathrm{e}}$} \\
\hline Never & 1347 & $(87.0)$ & 1258 & $(83.6)$ \\
\hline Ever & 202 & $(13.0)$ & 246 & $(16.4)$ \\
\hline \multicolumn{5}{|c|}{ a Previously published in Gammon et al. (2002). } \\
\hline \multicolumn{5}{|c|}{ b Previously published in Gammon et al. (2004a). } \\
\hline \multicolumn{5}{|c|}{ c Previously published in Steck et al. (2007). } \\
\hline \multicolumn{5}{|c|}{ d previously published in Mordukhovich et al. (2016). } \\
\hline e Prev & al. $(20$ & & & \\
\hline
\end{tabular}

analyses as demonstrated by the smaller credible limit ratios (CrLRs). These hierarchical results were slightly attenuated from the single exposure estimates when modeling each PAH source individually. Results from the single exposure models are similar to, but differ slightly from results published previously (Gammon et al., 2004a; Mordukhovich et al., 2016; Steck et al., 2007; White et al., 2014) due to changes in variable characterizations, analytic approach and adjustment set. In the multivariable analysis, there was some evidence of attenuation in comparison to the single exposure estimates.

The overall fixed estimates for the PAH sources (2nd level estimates for active smoking, residential ETS, diet, stove/fireplace use and 1st level estimate of vehicular traffic) from the hierarchical model showed little evidence of an association with breast cancer incidence, with estimates close to null or imprecise (Table 3).

We estimated the prevalence of each exposure profile in the LIBCSP study population. $<2 \%$ of women were characterized as having a low PAH exposure profile ( $n=26$ cases and $n=21$ controls) (Table 4). Very few women were considered exposed across all five PAH sources or by all the sources of inhalation $(<1 \%)$, whereas about $10 \%$ of cases and controls were exposed across the indoor sources of PAH (active smoking, residential ETS, high overall grilled/smoked foods and stove/ fireplace users).

The OR for the association between breast cancer incidence and the indoor exposure source profile of PAH was elevated by 1.46 $(\mathrm{OR}=1.45,95 \% \mathrm{CrI} 1.02,2.04 ; \mathrm{CrLR}=1.99)$ (Table 4). Among women who were highly exposed to PAH via ingestion, the effect estimate was elevated by 1.44 ( OR $=1.44,95 \% \mathrm{CrI} 1.16,1.78$; $\mathrm{CrLR}=$ 1.53). Estimates were elevated for women who used stove/fireplaces in their home, burning both wood and synthetic logs ( OR = 1.29, 95\% $\mathrm{CrI}=1.03,1.59)$. Exposure profiles that included vehicular traffic exposure were imprecise due to the small number of people who were classified as highly exposed. The ORs for these exposure profiles were calculated based on linear combinations from the hierarchical model.

A sensitivity analysis was conducted with long-term exposure to vehicular traffic from 1960 to 1990 included in the model, as long-term exposure has been found to be more strongly associated with breast cancer incidence in this study population (Mordukhovich et al., 2016). Inclusion of long-term vehicular traffic did not strengthen the fixedeffects for vehicular traffic exposure (data not shown). The large amount of missing data for long-term vehicular traffic precluded this $\mathrm{PAH}$ source from being included in the primary analysis. Long-term exposure to vehicular traffic is highly correlated with 1995 exposure and thus, 1995 estimates may be a sufficient proxy for long-term vehicular traffic (Mordukhovich et al., 2016). When considering an alternative $Z$-matrix specification with a second-level model comprised of ingestion and inhalation, second-level estimates were similar (Supplemental Table III). Results were similar when limiting to postmenopausal women with ER + tumors only (data not shown), although the estimates of association for grilled/smoked meat intake were slightly more pronounced. 
Table 2

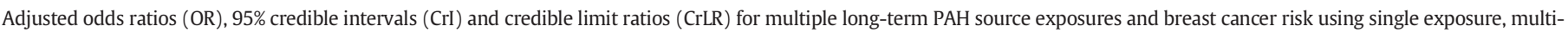
variable and hierarchical analyses, LIBCSP $1996-1997^{\mathrm{a}}$.

\begin{tabular}{|c|c|c|c|c|c|c|c|}
\hline \multirow[t]{2}{*}{ PAH source $(\pi)$} & \multirow[t]{2}{*}{ PAH variables $(\beta)^{\mathrm{b}}$} & \multicolumn{2}{|l|}{ Single exposure ${ }^{c}$} & \multicolumn{2}{|c|}{ Multivariable analysis } & \multicolumn{2}{|c|}{ Hierarchical analysis } \\
\hline & & OR (95\%CrI) & CrLR & OR (95\%CrI) & CrLR & OR (95\% CrI) & CrLR \\
\hline \multirow[t]{3}{*}{ Active smoking } & Ever active smoking & $1.04(0.89,1.22)$ & 1.37 & $1.03(0.75,1.37)$ & 1.83 & $1.01(0.83,1.21)$ & 1.45 \\
\hline & Current active smoking & $1.15(0.93,1.40)$ & 1.51 & $1.15(0.91,1.44)$ & 1.57 & $1.09(0.91,1.30)$ & 1.43 \\
\hline & Smoked before first pregnancy & $1.01(0.85,1.18)$ & 1.39 & $0.94(0.68,1.26)$ & 1.85 & $0.97(0.79,1.17)$ & 1.47 \\
\hline \multirow[t]{2}{*}{ Residential ETS } & Ever residential ETS & $1.08(0.90,1.30)$ & 1.44 & $0.92(0.74,1.15)$ & 1.55 & $1.00(0.82,1.19)$ & 1.45 \\
\hline & Ever residential ETS from spouse & $1.27(1.07,1.48)$ & 1.38 & $1.28(1.07,1.54)$ & 1.44 & $1.20(1.03,1.40)$ & 1.36 \\
\hline \multirow[t]{3}{*}{ Diet } & Total grilled/bbq and smoked meats & $1.34(1.13,1.59)$ & 1.41 & $1.21(0.94,1.51)$ & 1.61 & $1.16(0.97,1.38)$ & 1.42 \\
\hline & Grilled/bbq beef, pork and lamb & $1.27(1.07,1.49)$ & 1.39 & $1.13(0.91,1.38)$ & 1.51 & $1.14(0.96,1.34)$ & 1.39 \\
\hline & Smoked beef, pork and lamb & $1.19(1.02,1.38)$ & 1.35 & $1.07(0.89,1.28)$ & 1.43 & $1.09(0.95,1.26)$ & 1.33 \\
\hline Vehicular traffic & 1995 vehicular traffic & $1.20(0.81,1.70)$ & 2.10 & $1.26(0.86,1.76)$ & 2.06 & $1.25(0.85,1.76)$ & 2.07 \\
\hline \multirow[t]{3}{*}{ Stove/fireplace use } & Ever any stove/fireplace use & $1.09(0.93,1.27)$ & 1.37 & $1.06(0.70,1.51)$ & 2.16 & $1.03(0.85,1.24)$ & 1.47 \\
\hline & Ever synthetic log burning & $1.46(1.18,1.82)$ & 1.58 & $1.47(1.15,1.86)$ & 1.62 & $1.29(1.06,1.57)$ & 1.49 \\
\hline & Ever wood burning & $1.05(0.90,1.23)$ & 1.37 & $0.92(0.62,1.31)$ & 2.05 & $0.98(0.80,1.17)$ & 1.47 \\
\hline
\end{tabular}

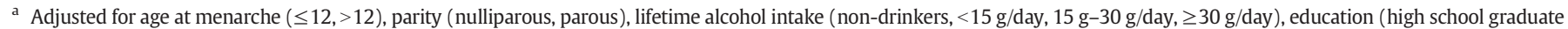
or less, some college, college or post-college), income $(<\$ 34,999, \$ 35,000-\$ 69,999, \geq \$ 70,000)$ and the matching factor, 5-year age group.

b See Table 1 for PAH variable cutpoints.

c Estimates do not exactly conform to previously published results, because of changes in variable definition and confounder adjustment (Gammon et al., 2004a; Steck et al., 2007; White et al., 2014; Mordukhovich et al., 2016).

\section{Discussion}

Women in this population-based sample from Long Island NY were exposed to PAHs across multiple sources, particularly active/passive smoking and grilled/smoked foods, and very few were classified as having a low PAH exposure profile, underscoring the ubiquitous nature of $\mathrm{PAH}$ exposure. We are the first to report that exposure across indoor sources of PAH (active smoking, residential ETS from spouse, grilled/ smoked meat intake, stove/fireplace use) was associated with a 1.46 increase in breast cancer incidence.

The results reported here are consistent with laboratory evidence (Hecht, 2002) and the existing epidemiologic literature on PAH sources and breast cancer incidence (Bonner et al., 2005; Crouse et al., 2010; Di Maso et al., 2013; Gaudet et al., 2013; Laden and Hunter, 1998; Lewis-Michl et al., 1996; Morabia et al., 1996; Nie et al., 2007). Consideration of all main PAH exposure sources concurrently in a single model provided effect estimates that better reflect the exposure complexity of multiple long-term PAH sources on breast cancer incidence. Tobacco smoke, indoor and outdoor air pollution and diet are modifiable breast cancer risk factors that can be reduced. The findings here suggest that all of the PAH sources considered are relevant; in particular the sources included in the indoor PAH exposure profile. Similar findings were found for PAH profiles of ingestion and inhalation. Thus, one exposure route may not necessarily be more important for breast cancer risk than the other.

Table 3

Fixed effects odds ratios (OR) and 95\% credible intervals ( $\mathrm{CrI}$ ) from hierarchical logistic regression models for the association between long-term PAH exposure, grouped by exposure sources, and breast cancer risk, LIBCSP 1996-1997 ${ }^{\text {a }}$

\begin{tabular}{ll}
\hline PAH exposure sources $(\pi)$ & OR $(95 \% \mathrm{CrI})$ \\
\hline Active smoking & $1.02(0.85,1.23)$ \\
Residential ETS & $1.10(0.86,1.40)$ \\
Diet & $1.13(0.93,1.36)$ \\
Vehicular traffic $^{\mathrm{b}}$ & $1.25(0.85,1.76)$ \\
Indoor stove/fireplace use & $1.09(0.90,1.31)$ \\
\hline
\end{tabular}

a Adjusted for age at menarche $(\leq 12,>12)$, parity (nulliparous, parous), lifetime alcohol intake (non-drinkers, $<15$ g/day, 15 g-30 g/day, $\geq 30$ g/day), education (high school graduate or less, some college, college or post-college), income $(<\$ 34,999, \$ 35,000-\$ 69,999, \geq \$ 70,000)$ and the matching factor, 5year age group.

b Vehicular traffic estimate is derived from first-level of hierarchical model because there is only one variable within that PAH source.
Vehicular traffic is often considered to be the largest source of PAHs in outdoor air pollution, particularly in urban locations (Dunbar et al., 2001). Among our population-based sample of women on Long Island NY, vehicular traffic was associated with an elevated, but also very imprecise, OR for breast cancer risk. Despite this, vehicular traffic did not notably increase $\mathrm{PAH}$ profile estimates (e.g., when comparing estimates for indoor sources of PAH to all five sources) likely due to the fact that only the top 5\% were considered exposed. This may not be the case in geographic locations where vehicular traffic exposure is higher and thus impacts more women.

The lack of associations observed with the fixed effects estimated by the second-level of the hierarchical model demonstrate that when averaging over the different PAH exposure variables, we do not observe a strong association between any of the PAH sources and breast cancer incidence. This finding emphasizes the importance of different exposure classifications, particularly those that incorporate relevant measures of intensity (for example, residential spouse ETS versus any residential ETS) or variability in exposure (for example, type of material burned in stove/fireplace).

Our study reported here has many strengths, in particular the population-based design. Additionally, this study has uniquely collected information on life course exposure to the main PAH sources. The use of Bayes hierarchical analysis to model these main sources concurrently, and their profile-level associations, is useful to better understand the impact of multiple sources of interest. Our results were only slightly attenuated when comparing single and hierarchical models, thus, these results are encouraging that at least in the case of these PAH sources, modeling them individually may produce similar results.

Several issues may impact interpretation of the study findings reported here. For example, self-reported exposure to the PAH sources could result in bias due to misclassification error in the PAH exposure markers. However, self-reported active cigarette smoking and ETS have been previously found to be a valid measurement (Patrick et al., 1994).Whether cases and controls reported these exposures differentially is unknown; however, at the time of LIBCSP data collection in the mid-1990s, most media attention in the Long Island NY area focused on the potential adverse effects of other environmental contaminants, including exposure to pesticides and electromagnetic fields, but not PAH sources (Gammon et al., 2002).

In a previous study in this population that considered associations with a single PAH exposure source, we did not find an association between wood-burning in the home and breast cancer incidence (White et al., 2014). Reports have been inconsistent on whether burning 
Table 4

Odds ratios (OR) and 95\% credible intervals (CI) from hierarchical regression models for the association between PAH exposure profiles and breast cancer risk, LIBCSP 1996-1996 ${ }^{\text {. }}$

\begin{tabular}{|c|c|c|c|c|}
\hline \multirow[t]{2}{*}{ PAH exposure profiles ${ }^{\mathrm{b}}$} & \multicolumn{2}{|c|}{$\begin{array}{l}\text { Controls }(N= \\
1556)\end{array}$} & \multicolumn{2}{|c|}{$\begin{array}{l}\text { Cases }(N= \\
1508)\end{array}$} \\
\hline & $\mathrm{N}$ & $\%$ & $\mathrm{~N}$ & $\%$ \\
\hline Low PAH exposure ${ }^{c}$ & 21 & $1.3 \%$ & 26 & $1.7 \%$ \\
\hline Tobacco smoke (active and ETS) $^{d}$ & 124 & $8.0 \%$ & 123 & $8.2 \%$ \\
\hline Ingested $\mathrm{PAHs} \mathrm{s}^{\mathrm{e}}$ & 504 & $32.4 \%$ & 531 & $35.2 \%$ \\
\hline Indoor stove/fireplace use ${ }^{f}$ & 168 & $10.8 \%$ & 206 & $13.7 \%$ \\
\hline Inhaled $\mathrm{PAHs}^{\mathrm{g}}$ & 15 & $1.0 \%$ & 18 & $1.2 \%$ \\
\hline Indoor source PAHs ${ }^{\mathrm{h}}$ & 166 & $10.7 \%$ & 160 & $10.6 \%$ \\
\hline Five $\mathrm{PAH}$ sources ${ }^{\mathrm{i}}$ & 9 & $0.6 \%$ & 9 & $0.6 \%$ \\
\hline
\end{tabular}

${ }^{a}$ Adjusted for age at menarche ( $\left.\leq 12,>12\right)$, parity (nulliparous, parous), lifetime alcohol intake (non-drinkers, $<15$ g/day, 15 g-30 g/day, $\geq 30$ g/day), education (high school graduate or less, some college, college or post-college), income $(<\$ 34,999, \$ 35,000$ $\$ 69,999, \geq \$ 70,000)$ and the matching factor, 5 -year age group. ORs and $95 \% \mathrm{CrI}$ are derived as linear combinations of the hierarchical regression estimates.

b See Table 1 for PAH variable cutpoints and Supplemental Table II for profile definitions.

c Non-active smoker, no residential ETS, low intake of grilled/smoked foods, low vehicular traffic emissions, no stove/fireplace use.

d Current, active smokers who started prior to first pregnancy and were exposed to residential ETS from spouse.

e High intake of overall grilled/smoked foods, grilled/barbecued beef, pork and lamb and smoked ham, pork and lamb.

${ }^{\mathrm{f}}$ Indoor stove/fireplace users, burned both wood and synthetic logs.

g Active smokers, residential ETS, top 5\% of vehicular traffic, stove/fireplace users.

h Active smokers, residential ETS spouse, high overall grilled/smoked foods and stove/ fireplace users.

i Active smokers, residential ETS, high overall grilled/smoked foods, stove/fireplace users and top $5 \%$ of vehicular traffic exposure.

synthetic or wood logs produce more PAHs (Gullett et al., 2003; Li and Rosenthal, 2006; McDonald et al., 2000; Nolan et al., 2006; Rogge et al., 1998; Watson et al., 1998). It is important to note that synthetic logs are designed to be used in open fireplaces, which tend to have higher PAH emissions than wood stoves (Traynor et al., 1987), and this may, at least in part, explain this differential association. However, we cannot rule out the possibility that recall bias may play some role in the association observed here with synthetic logs and breast cancer incidence.

Estimating vehicular traffic exposure was dependent upon each participant recalling her residential history, and the accuracy of the participant reporting this information is unlikely to be associated with her case-control status. Thus, any misclassification error associated with this exposure is likely to be non-differential. Yet, the OR associated with high vehicular traffic exposure was stronger in magnitude but with wide credible intervals in the hierarchical model. We did not consider occupational ETS exposure, which may have also contributed to PAH exposure.

Importantly, the PAH sources characterized here also contain other non-PAH chemicals, some of which may also be relevant to carcinogenesis (IARC, 2010). Although other chemicals in the PAH sources may be relevant to breast cancer, there is a strong biologic rationale that PAHs have a role in breast carcinogenesis (Brody et al., 2007; Gammon and Santella, 2008; Hecht, 2002).

Other carcinogens that are prominent in these PAH sources include polychlorinated biphenyls (PCBs) (Gullett et al., 2003), particulate matter (Gullett et al., 2003), aromatic and heterocyclic aromatic amines (Taylor et al., 2009; Terry and Rohan, 2002), N-nitrosamines (Terry and Rohan, 2002), dioxins (Danjou et al., 2015) and benzene (IOM (Institute of Medicine), 2012). PCBs, which may be released from indoor stove/fireplace use, may have both positive and inverse associations with breast cancer depending on the specific compound (Cohn et al., 2012; Recio-Vega et al., 2011) although evidence is based on few studies and not consistent (Brauner et al., 2014; Brody et al., 2007). The association between dioxins, which has been measured in meat, and breast cancer incidence has been inconsistent (Danjou et al., 2015; Warner et al., 2011). Research on the health effects of the air pollutant benzene has historically focused on occupationally-exposed men (IOM (Institute of Medicine), 2012). However, a study in New York did find an association among women who were likely to have moderate to high exposure based on job-exposure matrices (Petralia et al., 1999) and an association was observed with ER-PR- tumors in the California Teacher's Cohort study (Garcia et al., 2015).

Particulate matter is often used as a proxy measure of air pollution, but particulate matter has not been widely hypothesized to be a potential biologic mechanism for the association between air pollution and breast cancer incidence although a few studies have considered a role with survival after breast cancer (Hu et al., 2013; Hung et al., 2012). Occupational exposure to aromatic amines, found in meat and tobacco smoke, has been found to be associated with up to a 10-fold increase in breast cancer incidence (de Vocht et al., 2009). Interactions between smoking and genetic polymorphisms in $N$-acetyltransferase enzymes, which function to metabolize amines, support the role of these chemicals in breast cancer incidence (Ochs-Balcom et al., 2007). While evidence exists to support possible associations with other carcinogens, particularly PCBs, dioxins, benzene and aromatic amines with breast cancer incidence, findings have not been as consistent as those for PAHs. Additionally, these compounds are not present in all of the environmental exposure sources included in this study; instead, the common thread is PAH.

Due to the large size of the study population and the retrospective nature of assessing many of the PAH exposure sources, we were unable to more thoroughly evaluate patterns of metabolism and distribution across different PAH sources. Studies that evaluate variability in these biologic measures by PAH source are needed for a better understanding of the differences in carcinogenicity across sources.

Residential information was available only for Long Island residences based on the design of the study questionnaire. Therefore, if a woman used a stove/fireplace at any home not on Long Island, information on that would not have been included in this study (White et al., 2014). The small number of women who were classified as low PAH exposure precluded us from considering associations by tumor subtype and potential effect measure modifiers. It is possible that PAH sources may be differentially associated with specific tumor subtypes and we were unable to address that. Patterns of exposure to the main PAH sources also has likely changed since the time of LIBCSP data collection (1996-1997), most significantly with the general decrease in tobacco use (Agaku et al., 2014). Finally, findings in this Long Island-based study population may not be generalizable to all women, since these women were predominately white and postmenopausal at diagnosis.

\section{Conclusions}

This epidemiologic study reports that experiencing a number of common PAH exposure sources is associated with a $30-50 \%$ increase in incidence. The indoor sources of exposure (active/passive smoking, grilled/smoked food intake, indoor stove/fireplace use considered together) had the strongest association with breast cancer and are among the most common sources of long-term PAH exposures identified in our population-based sample of women on Long Island, NY. This study provides support for existing public health strategies to reduce cigarette smoking and vehicular traffic exposure, as well as targeting other PAH sources in an effort to reduce a woman's risk of developing breast cancer.

\section{Conflicts of interest}

None declared. 


\section{Sources of funding}

Supported in part by National Institute of Health grants: CA/ ES66572, ES07018, ES10126, ES019459, CA094061 and CA57726.

\section{Appendix A. Supplemental information}

Supplementary data to this article can be found online at http://dx. doi.org/10.1016/j.envint.2016.02.009.

\section{References}

Agaku, I.T., King, B.A., Dube, S.R., Centers for Disease Control Prevention, 2014. Current cigarette smoking among adults-United States, 2005-2012. MMWR Morb. Mortal. Wkly Rep. 63, 29-34.

American Cancer Society, 2014. Breast Cancer Facts and Figures 2014S. American Cancer Society, Atlanta, GA.

Beyea, J., Hatch, M., Stellman, S.D., Santella, R.M., Teitelbaum, S.L., Prokopczyk, B., et al., 2006. Validation and calibration of a model used to reconstruct historical exposure to polycyclic aromatic hydrocarbons for use in epidemiologic studies. Environ. Health Perspect. 114, 1053-1058.

Beyea, J., Stellman, S.D., Teitelbaum, S., Mordukhovich, I., Gammon, M.D., 2013. Imputation method for lifetime exposure assessment in air pollution epidemiologic studies. Environ. Health 12, 62

Bonner, M.R., Han, D.W., Nie, L., Rogerson, P., Vena, J.E., Muti, P., et al., 2005. Breast cancer risk and exposure in early life to polycyclic aromatic hydrocarbons using total suspended particulates as a proxy measure. Cancer Epidemiol. Biomark. Prev. 14, 53-60.

Boström, C.E., Gerde, P., Hanberg, A., Jernstrom, B., Johansson, C., Kyrklund, T., et al., 2002. Cancer risk assessment, indicators, and guidelines for polycyclic aromatic hydrocarbons in the ambient air. Environ. Health Perspect. 110 (Suppl. 3), 451-488.

Bradshaw, PT, Khankari, N.K. Teitelbaum, S.L, Xu, X, Fink, B.N. Steck, S.E, et al, 2013. Nutrient pathways and breast cancer risk: the Long Island Breast Cancer Study Project. Nutr. Cancer 65, 345-354.

Brauner, E.V., Loft, S., Wellejus, A., Autrup, H., Tjonneland, A., Raaschou-Nielsen, O., 2014 Adipose tissue PCB levels and CYP1B1 and COMT genotypes in relation to breast cancer risk in postmenopausal Danish women. Int. J. Environ. Health Res. 24, 256-268.

Brody, J.G., Moysich, K.B., Humblet, O., Attfield, K.R., Beehler, G.P., Rudel, R.A., 2007. Environmental pollutants and breast cancer: epidemiologic studies. Cancer 109, 2667-2711

Casella, G., George, E.I., 1992. Explaining the Gibbs sampler. Am. Stat. 46, 167-174.

Cohn, B.A., Terry, M.B., Plumb, M., Cirillo, P.M., 2012. Exposure to polychlorinated biphenyl (PCB) congeners measured shortly after giving birth and subsequent risk of maternal breast cancer before age 50. Breast Cancer Res. Treat. 136, 267-275.

Crouse, D.L., Goldberg, M.S., Ross, N.A., Chen, H., Labreche, F., 2010. Postmenopausal breast cancer is associated with exposure to traffic-related air pollution in Montreal, Canada: a case-control study. Environ. Health. Perspect. 118.

Danjou, A.M., Fervers, B., Boutron-Ruault, M.-C., Philip, T., Clavel-Chapelon, F., Dossus, L., 2015. Estimated dietary dioxin exposure and breast cancer risk among women from the French E3N prospective cohort. Breast Cancer Res. 17, 39.

de Vocht, F., Sobala, W., Wilczynska, U., Kromhout, H., Szeszenia-Dabrowska, N., Peplonska, B., 2009. Cancer mortality and occupational exposure to aromatic amines and inhalable aerosols in rubber tire manufacturing in Poland. Cancer. Epidemiol. 33, 94-102.

Di Maso, M., Talamini, R., Bosetti, C., Montella, M., Zucchetto, A., Libra, M., et al., 2013. Red meat and cancer risk in a network of case-control studies focusing on cooking practices. Ann. Oncol. 24, 3107-3112.

Dunbar, J.C., Lin, C.I., Vergucht, I., Wong, J., Duran, J.L., 2001. Estimating the contributions of mobile sources of PAH to urban air using real-time PAH monitoring. Sci. Total Environ. 279, 1-19.

Fu, Z., Deming, S.L., Fair, A.M., Shrubsole, M.J., Wujcik, D.M., Shu, X.O., et al., 2011. Welldone meat intake and meat-derived mutagen exposures in relation to breast cancer risk: the Nashville Breast Health Study. Breast Cancer Res. Treat. 129, 919-928.

Gammon, M.D., Santella, R.M., 2008. PAH, genetic susceptibility and breast cancer risk: an update from the Long Island breast cancer study project. Eur. J. Cancer 44, 636-640.

Gammon, M.D., Neugut, A.I., Santella, R.M., Teitelbaum, S.L., Britton, J.A., Terry, M.B., et al 2002. The Long Island Breast Cancer Study Project: description of a multi-institutional collaboration to identify environmental risk factors for breast cancer. Breast Cance Res. Treat. 74, 235-254.

Gammon, M.D., Eng, S.M., Teitelbaum, S.L., Britton, J.A., Kabat, G.C., Hatch, M., et al., 2004a. Environmental tobacco smoke and breast cancer incidence. Environ. Res. 96, 176-185.

Gammon, M.D., Sagiv, S.K., Eng, S.M., Shantakumar, S., Gaudet, M.M., Teitelbaum, S.L., et al., 2004b. Polycyclic aromatic hydrocarbon-DNA adducts and breast cancer: a pooled analysis. Arch. Environ. Health 59, 640-649.

Garcia, E., Hurley, S., Nelson, D.O., Hertz, A., Reynolds, P., 2015. Hazardous air pollutants and breast cancer risk in California teachers: a cohort study. Environ. Health 14,14.

Gaudet, M.M., Gapstur, S.M., Sun, J., Diver, W.R., Hannan, L.M., Thun, M.J., 2013. Active smoking and breast cancer risk: original cohort data and meta-analysis. J. Natl. Cancer Inst. 105, 515-525.

Gelman, A., Hill, J., 2006. Data Analysis Using Regression and Multilevel/Hierarchical Models. Cambridge University Press.
Glymour, M.M., Greenland, S., 2008. Causal diagrams. Modern Epidemiology, third ed. PA: Lippincott Williams \& Wilkins, Philadelphia.

Greenland, S., 2000. When should epidemiologic regressions use random coefficients? Biometrics 56, 915-921.

Gullett, B.K., Touati, A., Hays, M.D., 2003. PCDD/F, PCB, HxCBz, PAH, and PM emission factors for fireplace and woodstove combustion in the San Francisco Bay region. Environ. Sci. Technol. 37, 1758-1765.

Hecht, S.S., 2002. Tobacco smoke carcinogens and breast cancer. Environ. Mol. Mutagen. 39, 119-126.

Hu, H., Dailey, A.B., Kan, H., Xu, X., 2013. The effect of atmospheric particulate matter on survival of breast cancer among US females. Breast Cancer Res. Treat. 139, 217-226.

Hung, R.J., Brennan, P., Malaveille, C., Porru, S., Donato, F., Boffetta, P., et al., 2004. Using hierarchical modeling in genetic association studies with multiple markers: application to a case-control study of bladder cancer. Cancer Epidemiol. Biomark. Prev. 13, 1013-1021.

Hung, L.-J., Tsai, S.-S., Chen, P.-S., Yang, Y.-H., Liou, S.-H., Wu, T.-N., et al., 2012. Traffic air pollution and risk of death from breast cancer in Taiwan: fine particulate matter (PM2. 5) as a proxy marker. Aerosol. Air Qual. Res. 12, 275-282.

IARC, 2010. Some non-heterocyclic polycyclic aromatic hydrocarbons and some related exposures. IARC Monographs on the Evaluation of Carcinogenic Risks to Humans/ World Health Organization, International Agency for Research on Cancer. IARC Working Group on the Evaluation of Carcinogenic Risks to Humans, pp. 1017-1606.

Ibrahim, J.G., Chen, M.-H., Lipsitz, S.R., Herring, A.H., 2005. Missing-data methods for generalized linear models: a comparative review. J. Am. Stat. Assoc. 100, 332-346.

Ibrahim, J.G., Chu, H., Chen, M.H., 2012. Missing data in clinical studies: issues and methods. J. Clin. Oncol. 30, 3297-3303.

IOM (Institute of Medicine), 2012. Breast Cancer and the Environment: A Life Course Approach. The National Academic Press, Washington, DC.

Laden, F., Hunter, D.J., 1998. Environmental risk factors and female breast cancer. Annu. Rev. Public Health 19

Lewis-Michl, E.L., Melius, J.M., Kallenbach, L.R., Ju, C.L., Talbot TO, Orr, M.F., et al., 1996. Breast cancer risk and residence near industry or traffic in Nassau and Suffolk Counties, Long Island, New York. Arch. Environ. Health 51.

Li, V.S., Rosenthal, S., 2006. Content and Emission Characteristics of Artificial Wax Firelogs Omni Environmental Services for EPA Reg 5/Environment Canada.

Li, D.H., Walcott, F.L., Chang, P., Zhang, W.Q., Zhu, J.J., Petrulis, E., et al., 2002. Genetic and environmental determinants on tissue response to in vitro carcinogen exposure and risk of breast cancer. Cancer Res. 62, 4566-4570.

McDonald, J.D., Zielinska, B., Fujita, E.M., Sagebiel, J.C., Chow, J.C., Watson, J.G., 2000. Fine particle and gaseous emission rates from residential wood combustion. Environ. Sci. Technol. 34, 2080-2091.

Menzie, C.A., Potocki, B.B., Santodonato, J., 1992. Exposure to carcinogenic PAHs in the environment. Environ. Sci. Technol. 26, 1278-1284.

Morabia, A., Bernstein, M., Heritier, S., Khatchatrian, N., 1996. Relation of breast cancer with passive and active exposure to tobacco smoke. Am. J. Epidemiol. 143.

Mordukhovich, I., Beyea, J., Herring, A.H., Hatch, M., Stellman, S.D., Teitelbaum, S., et al., 2016. Exposure to traffic-related polycyclic aromatic hydrocarbons and breast cancer risk. Environ. Health Perspect. 124 (1), 30-38.

Nie, J., Beyea, J., Bonner, M.R., Han, D., Vena, J.E., Rogerson, P., et al., 2007. Exposure to traffic emissions throughout life and risk of breast cancer: the Western New York Exposures and Breast Cancer (WEB) study. Cancer Causes Control 18, 947-955.

Nolan, J., Pitzman, L., Eagle, B., Smith, R., Houck, J.E., 2006. Dioxin/Furan Air Emissions, General Emissions, and Fuel Composition of Duraflame Firelogs and Douglas Fir Cordwood.

Ochs-Balcom, H.M., Wiesner, G., Elston, R.C., 2007. A meta-analysis of the association of $\mathrm{N}$ acetyltransferase 2 gene (NAT2) variants with breast cancer. Am. J. Epidemiol. 166, 246-254.

Patrick, D.L., Cheadle, A., Thompson, D.C., Diehr, P., Koepsell, T., Kinne, S., 1994. The validity of self-reported smoking: a review and meta-analysis. Am. J. Public Health 84, $1086-1093$.

Petralia, S.A., Vena, J.E., Freudenheim, J.L., Dosemeci, M., Michalek, A., Goldberg, M.S., et al., 1999. Risk of premenopausal breast cancer in association with occupational exposure to polycyclic aromatic hydrocarbons and benzene. Scand. J. Work Environ. Health 25, 215-221.

Plummer, M., 2003. JAGS: a program for analysis of Bayesian graphical models using Gibbs sampling. Proceedings of the Proceedings of the 3rd international Workshop on Distributed Statistical Computing. 124, p. 125 Vienna.

Raaschou-Nielsen, O., Andersen, Z.J., Hvidberg, M., Jensen, S.S., Ketzel, M., Sorensen, M., et al., 2011. Air pollution from traffic and cancer incidence: a Danish cohort study. Environ. Health 10, 67.

Recio-Vega, R., Velazco-Rodriguez, V., Ocampo-Gomez, G., Hernandez-Gonzalez, S., RuizFlores, P., Lopez-Marquez, F., 2011. Serum levels of polychlorinated biphenyls in Mexican women and breast cancer risk. J. Appl. Toxicol. 31, 270-278.

Rogge, W.F., Hildemann, L.M., Mazurek, M.A., Cass, G.R., Simoneit, B.R.T., 1998. Sources of fine organic aerosol. 9. Pine, oak and synthetic log combustion in residential fireplaces. Environ. Sci. Technol. 32, 13-22.

Rundle, A., Tang, D.L., Hibshoosh, H., Estabrook, A., Schnabel, F., Cao, W.F., et al., 2000. The relationship between genetic damage from polycyclic aromatic hydrocarbons in breast tissue and breast cancer. Carcinogenesis 21, 1281-1289.

Steck, S.E., Gaudet, M.M., Eng, S.M., Britton, J.A., Teitelbaum, S.L., Neugut, A.L., et al., 2007. Cooked meat and risk of breast cancer - lifetime versus recent dietary intake. Epidemiology 18

Su Y-S, Yajima M. 2012. R2jags: A Package for Running Jags from R. R Package Version 003-08, URL http://CRAN.R-project.org/package=R2jags.

Taylor, V.H., Misra, M., Mukherjee, S.D., 2009. Is red meat intake a risk factor for breast cancer among premenopausal women? Breast Cancer Res. Treat. 117, 1-8.

Terry, P.D., Rohan, T.E., 2002. Cigarette smoking and the risk of breast cancer in women: a review of the literature. Cancer Epidemiol. Biomark. Prev. 11. 
Traynor, G.W., Apte, M.G., Carruthers, A.R., Dillworth, J.F., Grimsrud, D.T., Gundel, L.A 1987. Indoor air pollution due to emissions from wood-burning stoves. Environ. Sci. Technol. 21, 691-697.

Warner, M., Mocarelli, P., Samuels, S., Needham, L., Brambilla, P., Eskenazi, B., 2011. Dioxin exposure and cancer risk in the Seveso Women's Health Study. Environ. Health Perspect. 119 (12), 1700-1705.

Watson JG, Fujita E, Chow JC, Zielinska B. 1998. Northern Front Range Air Quality Study Final Report. Desert Research Institute.
White, A.J., Teitelbaum, S., Stellman, S.D., Beyea, J., Steck, S.E., Mordukhovich, I., et al., 2014. Indoor air pollution exposure from use of indoor stoves and fireplaces in association with breast cancer: a case-control study. Environ. Heal. 13, 108.

Witte, J.S., Greenland, S., Haile, R.W., Bird, C.L., 1994. Hierarchical regression analysis applied to a study of multiple dietary exposures and breast cancer. Epidemiology 5 , 612-621. 